\title{
Development of a nanocomposite chemiresistor sensor based on $\pi$ - conjugated azo polymer and graphene blend for detection of dissolved oxygen
}

\author{
André Olean-Oliveira, Marcos F.S. Teixeira* \\ Department of Chemistry and Biochemistry - School of Science and Technology, University of State of Sao Paulo (UNESP), Rua Roberto Simonsen, 305, CEP 19060-900 \\ Presidente Prudente, SP, Brazil
}

A R T I C L E I N F O

\section{Keywords:}

Azo conductive polymers

Chemiresistor

Nanocomposite

Oxygen sensor

Graphene

\begin{abstract}
A B S T R A C T
The present paper describes the electrochemical impedance activity of a hybrid film with graphene and poly(azoBismarck Brown Y) as the chemiresistor material. This nanocomposite film exhibits interesting properties based on the redox properties of the azo polymer combined with the great electronic conductivity and stability of graphene. Electrochemical impedance spectroscopy at the poly(azo-BBY)-rGO electrode in solutions with different dissolved $\mathrm{O}_{2}$ concentrations revealed that the resistance values are very sensitive to variations in the $\mathrm{O}_{2}$ concentration.
\end{abstract}

\section{Introduction}

Chemiresistors represent a new class and emerging area of electrochemical sensors $[1,2]$. Their operation is based on the change in the electrical resistance of the material due to chemical interaction with the analyte [3]. A variety of materials have been investigated for application as chemiresistors, such as semiconductor metal oxides [4], conductive polymers [5], organic semiconductors [6] and carbon-based materials [7,8]. Most chemiresistors are developed for gas sensing [8-10], with a few works dedicated to the sensing of chemical species in electrolyte solutions [11,12].

Composite materials classically combine two or more materials to take advantage of the best properties and characteristics of each [13]. Polymer-graphene nanocomposites prepared by combining the vast $\pi$ conjugated system of conducting polymers with the various properties of graphene have been highlighted [14-16]. In the case of azo conductive polymers (azo polymer), in addition to the advantages of being a conductive polymer, it still has the advantage of the presence of redox active sites due to the inclusion of diazonium groups in the polymer [17].

Here, we investigate the charge transfer of poly(azo-Bismark Brown $\mathrm{Y})$ with rGO (poly(azo-BBY)-rGO) in the presence of different concentrations of molecular oxygen with the objective of constructing a chemiresistor sensor for monitoring dissolved oxygen in aqueous solution.

\section{Experimental}

All measurements were performed in a conventional electrochemical cell containing three electrodes: a saturated calomel electrode (SCE) as the reference; platinum wire as the counter electrode and a fluoride-doped tin oxide (FTO) electrode coated with a poly(azo-BBY)rGO blend as the working electrode $\left(1.0 \mathrm{~cm}^{2}\right)$. All electrochemical measurements were performed with Palsens3 interfaced PSTrace 5.2 software. All reagents used were of high purity $\geq 98 \%$ (Sigma Aldrich).

The poly(azo-BBY)-rGO sensor material was prepared on the FTO surface by potential cycling between -0.30 and $+1.00 \mathrm{~V}$ (vs. SCE) for 20-cycle scans at a scan rate of $10 \mathrm{mV} \mathrm{s}^{-1}$ in a deaerated solution containing $10 \mathrm{mmol} \mathrm{L}^{-1} \mathrm{BBY}$ and a $1.00 \mathrm{mg} \mathrm{mL}^{-1}$ suspension of graphene oxide (Sigma Aldrich) in a $0.1 \mathrm{~mol} \mathrm{~L}^{-1} \mathrm{HCl}$ medium.

The charge transfer resistance of the polymer composite with molecular oxygen in a solution of $0.5 \mathrm{~mol} \mathrm{~L}^{-1} \mathrm{KCl}(\mathrm{pH} 2.0)$ and $0.05 \mathrm{~mol} \mathrm{~L}^{-1}$ phosphate buffer ( $\mathrm{pH} 7.4$ ) was investigated using EIS measurements at an applied potential of $-0.30 \mathrm{~V}$ (vs. SCE). The pH solutions were adjusted with hydrochloridric acid and sodium hydroxide.

The EIS measurements were performed through the incidence of a sine wave of $10 \mathrm{mV}$ applied in a frequency range of $50 \mathrm{kHz}$ to $0.1 \mathrm{~Hz}$ with $10 \mathrm{step} / \mathrm{dec}$. All spectra were recorded at $25^{\circ} \mathrm{C}$. The analysis of the complex plane impedance spectra was determined by ZPlot 2.4 software. The determination of dissolved oxygen was performed after the addition of an aliquot of a $\mathrm{Na}_{2} \mathrm{SO}_{3}$ standard solution $\left(0.1 \mathrm{~mol} \mathrm{~L}^{-1}\right)$. The

\footnotetext{
* Corresponding author.

E-mail address: marcos.fs.teixeira@unesp.br (M.F.S. Teixeira).
} 

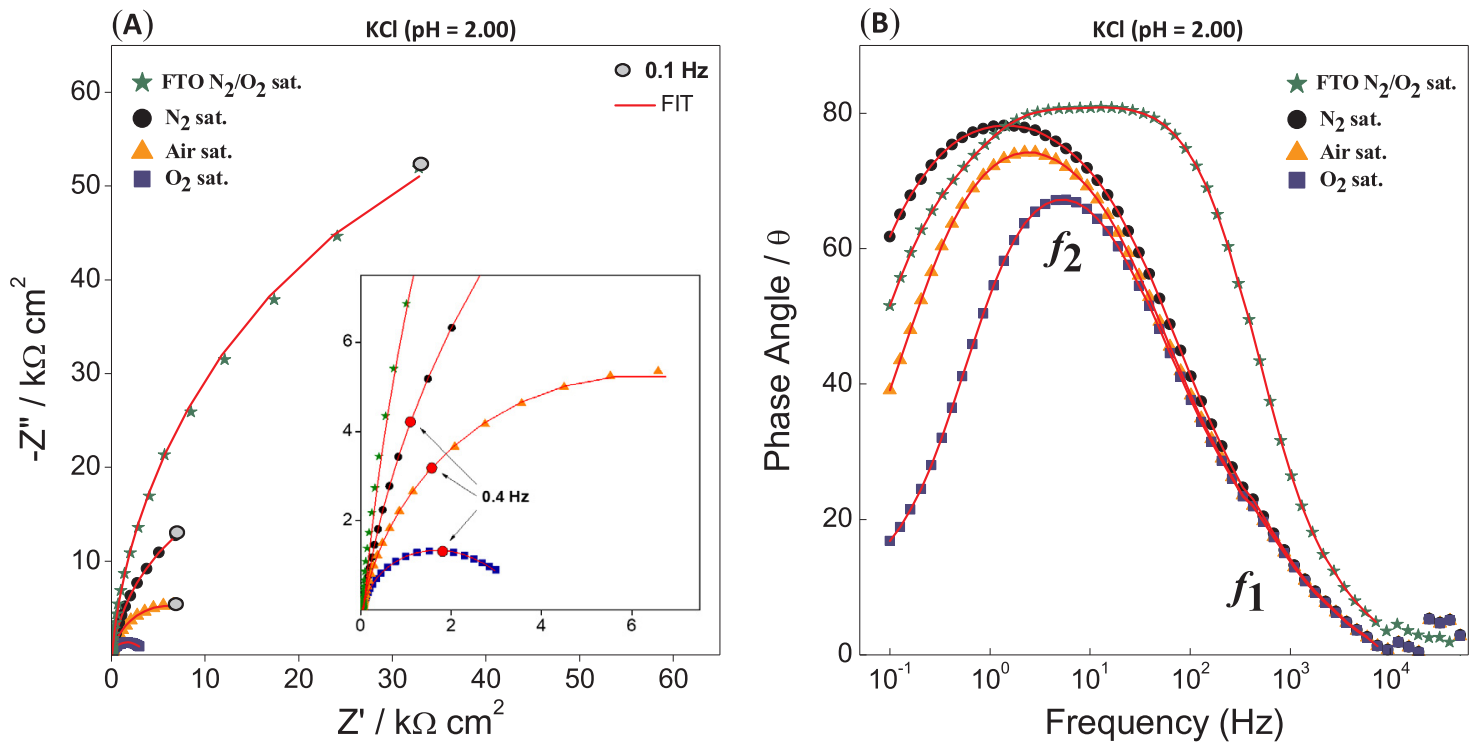

(c)

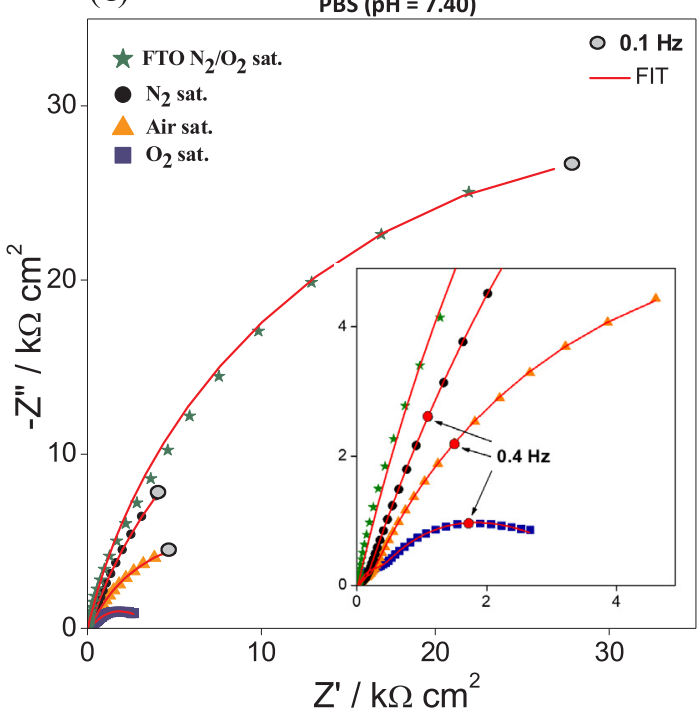

(D)

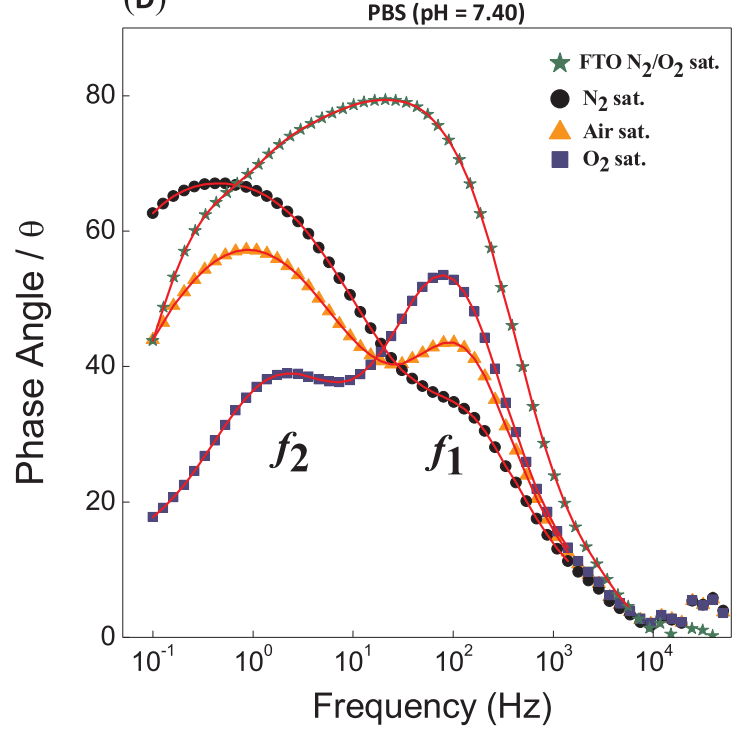

(E)

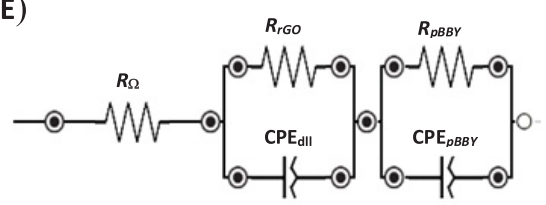

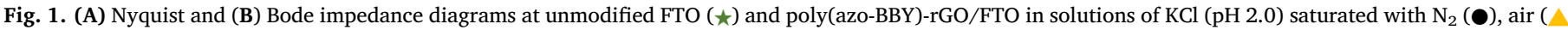

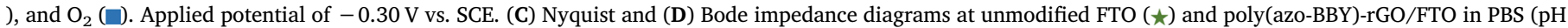

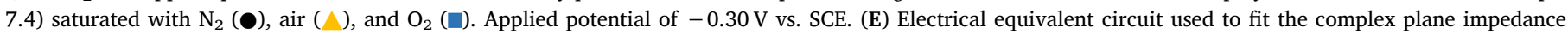
spectra at poly(azo-BBY)-rGO/FTO.

gas concentration was calculated from the chemical reaction of oxygen consumption by sulfite.

\section{Results and discussion}

\subsection{Performance of the sensing platform}

The poly(azo-BBY)-rGO film was studied by EIS, which provided important information about the physical and interfacial properties of the sensing platform. Fig. 1 show the typical impedance datas (Nyquist and Bode) obtained at the composite electrode in $\mathrm{KCl}(\mathrm{pH} 2.0)$ and PBS (pH 7.4) in the absence of oxygen and in the presence of normal and saturated oxygen levels. To analyze the characteristics of the impedance plot, an equivalent circuit (Fig. 1E) composed of a cell resistance $\left(R_{\Omega}\right)$ in series with two parallel $R$ CPE combinations was used to fit the spectra. The first $R$ CPE combination is associated with the solution/rGO interface $\left(R_{p G O}\right.$ and $\left.\mathrm{CPE}_{d l}\right)$, while the second $R$ CPE combination is attributed with the $\mathrm{rGO} /$ polymer interface $\left(R_{p B B Y}\right.$ and $\left.\mathrm{CPE}_{p B B Y}\right)$, and their values (Table 1 ) depend on the oxygen content and $\mathrm{pH}$ of the aqueous solution. 
Table 1

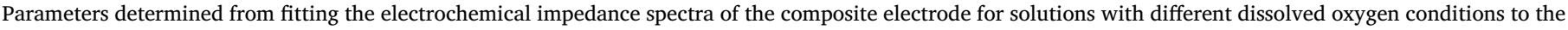
equivalent circuit shown in Fig. 1E. The errors presented for the fit were below $2 \%$.

\begin{tabular}{|c|c|c|c|c|c|c|c|}
\hline & $R_{\Omega}$ & $\begin{array}{c}R_{r G O} \\
\left(\mathrm{k} \Omega \mathrm{cm}^{2}\right)\end{array}$ & $R_{p B B Y}$ & $\begin{array}{l}\mathrm{CPE}_{d l} \\
\left(\mathrm{mF} \mathrm{cm}^{-2} \mathrm{~s}^{\alpha-1}\right)\end{array}$ & $\alpha_{d l}$ & $\begin{array}{l}\mathrm{CPE}_{p B B Y} \\
\left(\mathrm{mF} \mathrm{cm}^{-2} \mathrm{~s}^{\alpha-1}\right)\end{array}$ & $\alpha_{p B B Y}$ \\
\hline \multicolumn{8}{|c|}{$\mathrm{KCl}(\mathrm{pH}=2.00)$} \\
\hline $\mathrm{N}_{2}$ sat. & 0.025 & 0.021 & 41.6 & 0.486 & 0.691 & 0.0937 & 0.901 \\
\hline Air sat. & 0.025 & 0.020 & 12.3 & 0.348 & 0.735 & 0.111 & 0.898 \\
\hline $\mathrm{O}_{2}$ sat. & 0.026 & 0.016 & 3.29 & 0.237 & 0.780 & 0.121 & 0.879 \\
\hline \multicolumn{8}{|c|}{ PBS $(\mathrm{pH}=7.40)$} \\
\hline $\mathrm{N}_{2}$ sat. & 0.047 & 0.085 & 49.6 & 0.160 & 0.800 & 0.103 & 0.790 \\
\hline Air sat. & 0.047 & 0.131 & 14.6 & 0.170 & 0.759 & 0.0380 & 0.922 \\
\hline $\mathrm{O}_{2}$ sat. & 0.046 & 3.050 & 2.55 & 0.022 & 0.999 & 0.180 & 0.721 \\
\hline
\end{tabular}

(A)

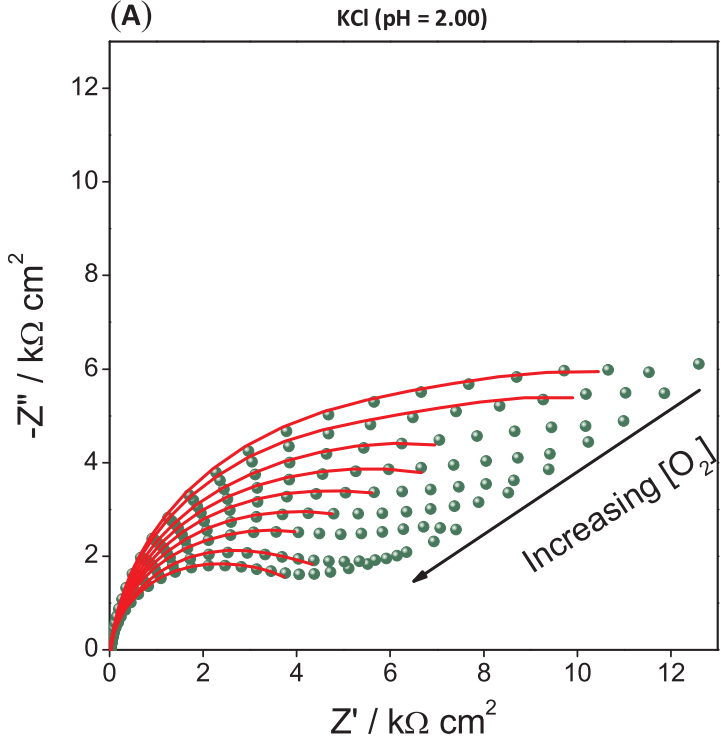

(B)

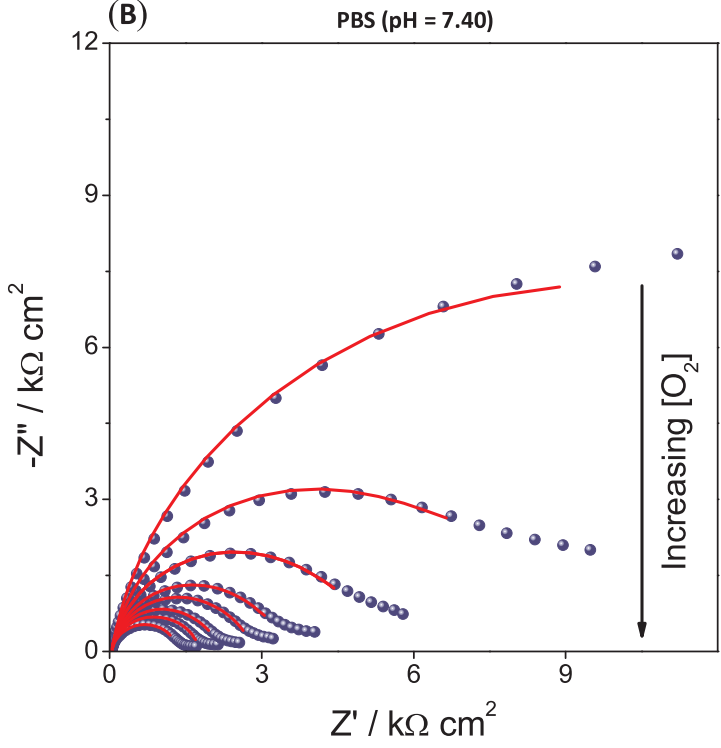

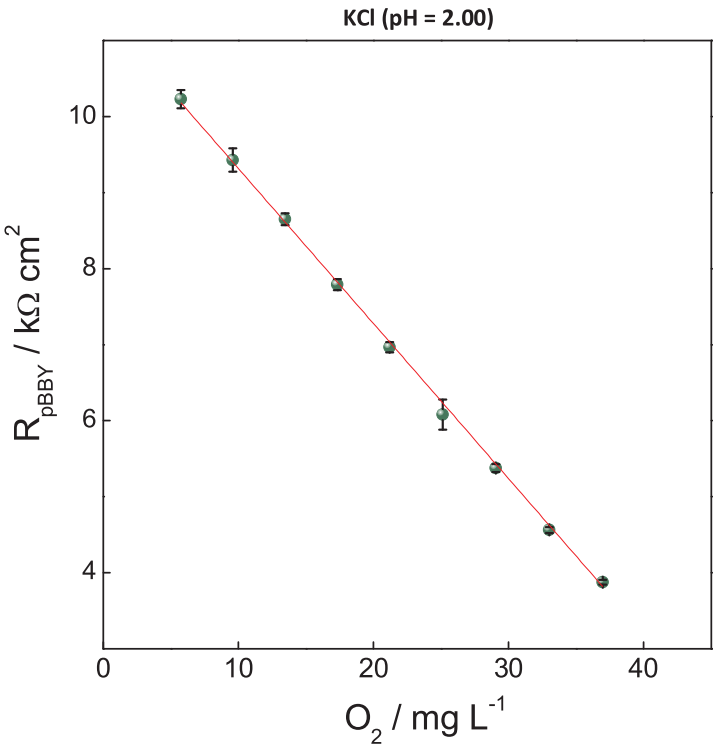

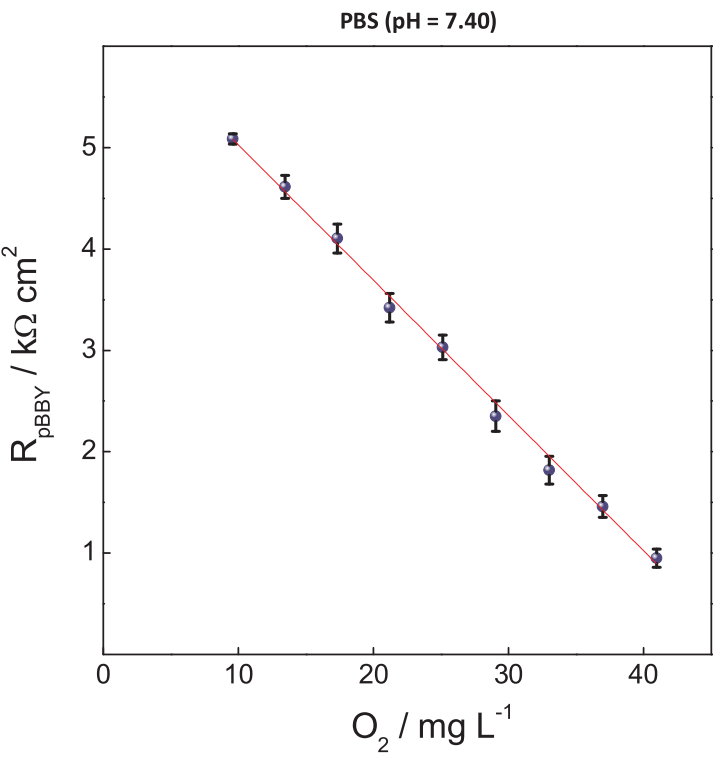

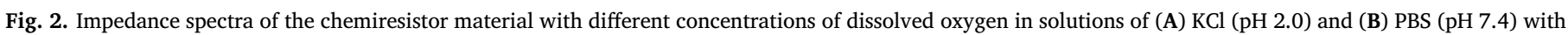
their respective calibration curves. The error bars represent the standard deviation from three separate experiments using the same sensor.

In the Bode plots (Fig. 1B and D), the resistive and capacitive regions are clearly distinguished together with the information provided by the frequency dependence of the phase angle $(\theta)$, which is a very sensitive indicator of small changes in such spectra [18]. As shown in Fig. 1B and D, it is possible to verify the presence of two constant phase elements (CPE) due to the presence of two phase angles located in the high-medium $\left(f_{1}\right)$ and medium-low $\left(f_{2}\right)$ frequency regions for both studied electrolytes [19]. It is clearly seen that in the acidic medium, the phase angles $\left(f_{1}\right)$ attributed to the solution/rGO interface were practically constant and that the polymer became more conductive in 


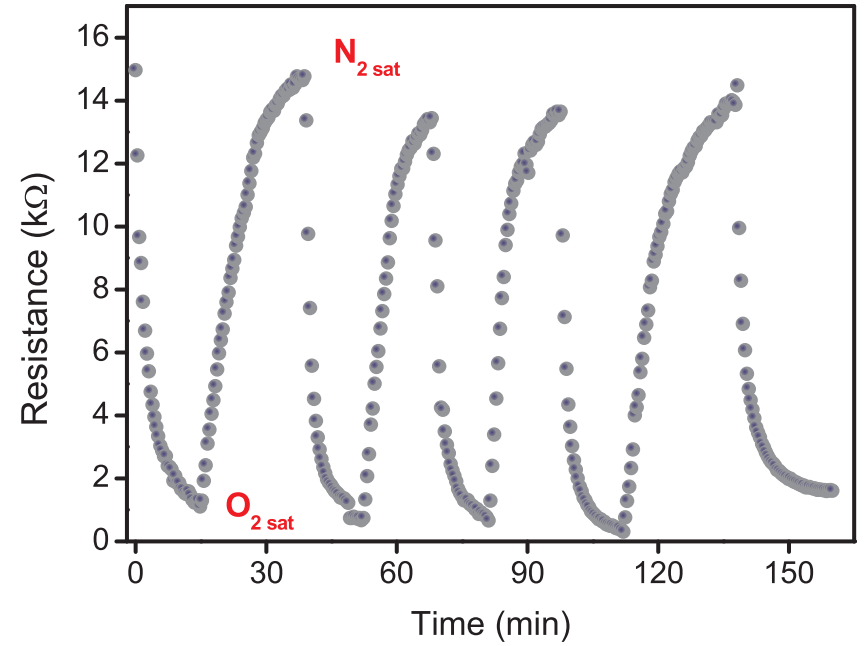

Fig. 3. Response of the poly(azo-BBY)-rGO film sensor as a function of time in $\mathrm{KCl}(\mathrm{pH} \mathrm{2.0})$ at a fixed frequency of $0.1 \mathrm{~Hz}$. Applied potential $=-0.30 \mathrm{~V}$ vs. SCE

the presence of molecular oxygen. At negative potentials, poly(azo$\mathrm{BBY}$ ) is in its reduced form (Eq. (1)) and can supply protons and electrons to the dissolved oxygen molecules.

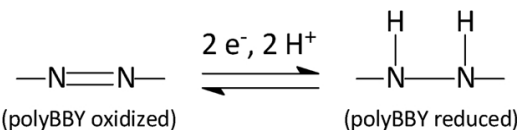

The decrease in the resistance results from the reaction between molecular oxygen and the hydrazine groups present in the polymer $[17,20]$. The electronic conductivity of the polymer is due to the $\pi$ conjugation present in the polymer chains [21].<smiles>C=NNC</smiles>

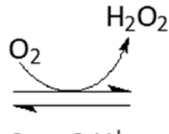

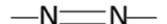

(polyBBY oxidized)
In PBS (Fig. 1D), contrary to the observed phase angle for the polymer, the presence of molecular oxygen increased the phase angle for the solution/rGO interface. From the EIS analysis (see Table 1), it is clear that the graphene on the film surface became more porous, and the resistance increased at the interface in the phosphate medium (slightly alkaline). This result can be attributed to the microoxidation of the graphene by molecular oxygen [22]. Padey and collaborators [23] reported that molecular oxygen could chemically adsorb on the graphene defects, and the oxidation process led to the formation of pits in the graphene. However, a more detailed study on the effect of the $\mathrm{pH}$ will be given later in a new work. Even so, the impedance related to the $\mathrm{rGO} /$ polymer interface decreased with variations in the dissolved oxygen concentration for low and medium frequencies. To confirm the recognition of dissolved $\mathrm{O}_{2}$ by the poly(azo-BBY) film, impedance spectra at an unmodified FTO electrode in solutions saturated with molecular oxygen and molecular nitrogen were recorded at $-0.30 \mathrm{~V}$ for both studied electrolytes (insert in Fig. 1A and C). There was no change in the spectral profile, indicating that at $-0.30 \mathrm{~V}$, there was no molecular oxygen reduction at the electrode surface.

\subsection{Chemiresistor response to dissolved oxygen}

The impedance response of the poly(azo-BBY)-rGO film to different concentrations of dissolved oxygen was examined in a $\mathrm{KCl}$ solution $\mathrm{pH}$ 2.0) and a PBS solution ( $\mathrm{pH} \mathrm{7.4)} \mathrm{at} \mathrm{frequencies} \mathrm{from} 50 \mathrm{kHz}$ to $0.1 \mathrm{~Hz}$ at an applied potential of $-0.30 \mathrm{~V}$ (vs. SCE). The Nyquist impedance diagrams recorded at the chemiresistor material with different dissolved $\mathrm{O}_{2}$ concentrations in $\mathrm{KCl}$ and PBS media are shown in Fig. 2A and $\mathrm{B}$, respectively.

The respective linear relationships between the resistance and $\mathrm{O}_{2}$ concentration in the range of $5.75 \mathrm{mg} \mathrm{L}^{-1}\left(0.018 \mathrm{mmol} \mathrm{L}^{-1}\right)$ to $40.9 \mathrm{mg} \mathrm{L}^{-1}\left(1.28 \mathrm{mmol} \mathrm{L}^{-1}\right)$ were represented by Eq. (3) and Eq. (4):

$R_{\mathrm{pBBY}}\left(\mathrm{k} \Omega \mathrm{cm}^{2}\right)=11.3 \pm 0.06-0.204 \pm 0.003\left[\mathrm{O}_{2}\left(\mathrm{mg} \mathrm{L}^{-1}\right)\right](\mathrm{n}=9$; $\left.\mathrm{R}^{2}=0.9989\right)$ for $\mathrm{KCl}(\mathrm{pH} 2.0)$

$R_{\mathrm{pBBY}}\left(\mathrm{k} \Omega \mathrm{cm}^{2}\right)=6.36 \pm 0.04-0.133 \pm 0.002\left[\mathrm{O}_{2}\left(\mathrm{mg} \mathrm{L}^{-1}\right)\right](\mathrm{n}=9$; $\left.\mathrm{R}^{2}=0.9985\right)$ for PBS (pH 7.4)

For the chemiresistor response, the decrease in the resistance $\left(\mathrm{R}_{p B B Y}\right)$ with increasing amount of $\mathrm{O}_{2}$ is related to an increase in the amount of charge transferred between the polymer and molecular oxygen. The impedance dynamic response of the poly(azo-BBY)-rGO/ FTO sensor (Fig. 3) was examined in $\mathrm{KCl}$ solutions saturated with $\mathrm{O}_{2}$ and $\mathrm{N}_{2}$, with the frequency fixed at $0.1 \mathrm{~Hz}$. The sensor exhibited good repeatability with a relative variation of $4.1 \%$ in the overall response of the chemiresistor per regeneration cycle.

\section{Conclusion}

The poly(azo-BBY)-rGO film exhibits a good $\mathrm{O}_{2}$ recognition ability in both acidic solution and slightly alkaline solution due to the high affinity of the hydrazine group with molecular oxygen. The resistance at the poly(azo-BBY)-rGO/FTO film increases linearly with decreasing amount of dissolved $\mathrm{O}_{2}$ in the electrolyte solution. Two calibration curves were developed, revealing sensitivities of $0.204 \mathrm{k} \Omega \mathrm{cm}^{2} \mathrm{~L} \mathrm{mg}^{-1}$ and $0.133 \mathrm{k} \Omega \mathrm{cm}^{2} \mathrm{~L} \mathrm{mg}^{-1}$ for $\mathrm{O}_{2}$ detection at $\mathrm{pH} 2.00$ and $\mathrm{pH} 7.40$, respectively. This chemiresistor material will be adapted for the measurement of mitochondrial oxygen consumption.

\section{Acknowledgments}

The authors acknowledge FAPESP (2016/09017-1) for financial support. A.O.O. thanks CAPES-Brazil for a master fellowship. SJT $\therefore$

\section{References}

[1] B. Raguse, E. Chow, C.S. Barton, L. Wieczorek, Gold nanoparticle chemiresistor sensors: direct sensing of organics in aqueous electrolyte solution, Anal. Chem. 79 (2007) 7333-7339.

[2] U. Lange, V.M. Mirsky, Polythiophene films on gold electrodes: a comparison of bulk and contact resistances in aqueous and organic media, J. Solid State Electr. 15 (2011) 2377-2382.

[3] U. Lange, V.M. Mirsky, Chemiresistors based on conducting polymers: a review on measurement techniques, Anal. Chim. Acta 687 (2011) 105-113.

[4] M.S. Yao, W.X. Tang, G.E. Wang, B. Nath, G. Xu, MOF. thin film-Coated metal oxide nanowire array: significantly improved chemiresistor sensor performance, Adv. Mater. 28 (2016) 5229-

[5] E. Song, J.W. Choi, Conducting polyaniline nanowire and its applications in chemiresistive sensing, Nanomater.-Basel 3 (2013) 498-523.

[6] H.L. Huang, D.E. Gross, X.M. Yang, J.S. Moore, L. Zang, One-step surface doping of organic nanofibers to achieve high dark conductivity and chemiresistor sensing of amines, Acs Appl. Mater. Interface 5 (2013) 7704-7708.

[7] B.K. Das, C. Tlili, S. Badhulika, L.N. Cella, W. Chen, A. Mulchandani, Single-walled carbon nanotubes chemiresistor aptasensors for small molecules: picomolar level detection of adenosine triphosphate, Chem. Commun. 47 (2011) 3793-3795.

[8] F. Rigoni, S. Tognolini, P. Borghetti, G. Drera, S. Pagliara, A. Goldoni, L. Sangaletti, Enhancing the sensitivity of chemiresistor gas sensors based on pristine carbon nanotubes to detect low-ppb ammonia concentrations in the environment, Analyst 138 (2013) 7392-7399.

[9] K. Fu, S.T. Chen, J. Zhao, B.G. Willis, Dielectrophoretic assembly of gold nanoparticles in nanoscale junctions for rapid, miniature chemiresistor vapor sensors, Acs Sens. 1 (2016) 444-450.

[10] S. Srinives, T. Sarkar, R. Hernandez, A. Mulchandani, Potassium iodideFunctionalized polyaniline nanothin film chemiresistor for ultrasensitive ozone gas sensing, Polym.-Basel 9 (2017).

[11] B. Raguse, C.S. Barton, K.H. Muller, E. Chow, L. Wieczorek, Gold nanoparticle chemiresistor sensors in aqueous solution: comparison of hydrophobic and hydrophilic nanoparticle films, J. Phys. Chem. C 113 (2009) 15390-15397.

[12] E. Chow, J. Herrmann, C.S. Barton, B. Raguse, L. Wieczorek, Inkjet-printed gold nanoparticle chemiresistors: influence of film morphology and ionic strength on the detection of organics dissolved in aqueous solution, Anal. Chim. Acta 632 (2009) 
$135-142$.

[13] P.A. Basnayaka, M.K. Ram, L. Stefanakos, A. Kumar, High performance graphenepoly (o-anisidine) nanocomposite for supercapacitor applications, Mater. Chem. Phys. 141 (2013) 263-271.

[14] S. Gupta, C. Price, Investigating graphene/conducting polymer hybrid layered composites as pseudocapacitors: interplay of heterogeneous electron transfer, electric double layers and mechanical stability, Compos. Part B-Eng. 105 (2016) 46-59.

[15] S. Gupta, E. Heintzman, C. Price, Electrostatic layer-by-layer self-assembled graphene/multi-walled carbon nanotubes hybrid multilayers as efficient 'All carbon' supercapacitors, J. Nanosci. Nanotechnol. 16 (2016) 4771-4782.

[16] S. Gupta, B. McDonald, S.B. Carrizosa, C. Price, Microstructure, residual stress, and intermolecular force distribution maps of graphene/polymer hybrid composites: nanoscale morphology-promoted synergistic effects, Compos. Part B-Eng. 92 (2016) 175-192.

[17] M.F.S. Teixeira, M.M. Barsan, C.M.A. Brett, Molecular engineering of a pi-conjugated polymer film of the azo dye Bismarck Brown Y, RSC Adv. 6 (2016) 101318-101322.

[18] J. Huang, Z. Li, B.Y. Liaw, J.B. Zhang, Graphical analysis of electrochemical impedance spectroscopy data in Bode and Nyquist representations, J. Power Sources 309 (2016) 82-98.

[19] P. Cordoba-Torres, T.J. Mesquita, R.P. Nogueira, Relationship between the origin of constant-phase element behavior in electrochemical impedance spectroscopy and electrode surface structure, J. Phys. Chem. C 119 (2015) 4136-4147.
[20] J.C. Forti, J.A. Nunes, M.R.V. Lanza, R. Bertazzoli, Azobenzene-modified oxygenfed graphite/PTFE electrodes for hydrogen peroxide synthesis, J. Appl. Electrochem. 37 (2007) 527-532.

[21] G.r. Inzelt, Conducting Polymers: a New Era in Electrochemistry, 2nd ed., Springer Heidelberg, New York, 2012.

[22] S.S. Yu, W.T. Zheng, Q. Jiang, Oxidation of graphene nanoribbon by molecular oxygen, Ieee Trans. Nanotechnol. 7 (2008) 628-635.

[23] G.X. Wang, R. Pandey, S.P. Karna, Physics and chemistry of oxidation of two-dimensional nanomaterials by molecular oxygen, Wires Comput. Mol. Sci. 7 (2017).

André Olean-Oliveira received the graduate degree in Chemistry from São Paulo State University (2016). At present, he is a postgraduate student (Master Science) in Chemistry at the Department of Chemistry and Biochemistry of the São Paulo State University and his research interests include chemical sensors (electrochemical and chemiresistor) and development of new materials as sensorial platform.

Marcos Fernando Souza Teixeira obtained his PhD degree (Analytical Chemistry) in 2000 at the Federal University of São Carlos. Currently, he is an associate professor at the Department of Chemistry and Biochemistry of the São Paulo State University (UNESP) Campus of Presidente Prudente. His research interests are in the development of chemical sensing concepts, electrochemical sensors based on polymeric sensing phases and environmental electroanalytical. 